\title{
自动化监控系统在中卫市南山台扬水洜站 更新改造工程中的应用
}

\section{Application of Automatic Monitoring System in the Renovation Project of Nanshantai Pumping Station in Zhongwei City}

\author{
黄秀芳 \\ Xiufang Huang \\ 宁夏中卫市水务局 中国·宁夏 中卫 755000 \\ Ningxia Zhongwei Water Bureau, Zhongwei, Ningxia, 755000, China
}

\begin{abstract}
摘 要: 论文将以中卫市南山台扬水原站综合自动化工程为例, 明确扬水原站更新改造工程自动化监控系统设计需求, 完成 包括网络及通信系统、计算机监控系统、微机保护系统、视频监视系统、软件系统等子系统的水原站更新改造工程自动化监测 系统设计, 以期能够提高中卫市南山台扬水原站自动化监测效果的同时,为其他同类工程提供理论参考。
\end{abstract}

\begin{abstract}
The paper will take the comprehensive automation project of Nanshantai pumping station in Zhongwei as an example to clarify the design requirements of the automation monitoring system for the upgrading and reconstruction of the pumping station, and complete the automatic monitoring system design of the water pumping station renovation project including network and communication system, computer monitoring system, microcomputer protection system, video monitoring system, software system and other subsystems, in order to improve the automatic monitoring effect of Nanshantai pumping station in Zhongwei, provide theoretical reference for other similar projects.
\end{abstract}

关键词: 自动化监测系统; 扬水原站更新改造工程;系统设计

Keywords : automatic monitoring system; the renovation project of pumping station; system design

DOI : $10.36012 /$ etr.v2i7.2189

\section{1 引言}

宁夏中卫市南山台扬水泵站是 20 世纪 70 年代兴建的 一项大型扶贫扬黄工程, 工程布置三级扬水, 建泵站 4 座, 设 计扬水流量 $6.65 \mathrm{~m}^{3} / \mathrm{s}$, 承担着沙坡头区永康、宣和 2 个镇 20 个行政村 22.3 万亩农田及硒砂瓜的灌溉任务。泵站建设, 受 当时经济、技术条件限制, 工程建设标准低,配套设施不完 善, 老化失修严重,机泵效率下降、带病运行、故障频繁发生, 严重威胁着泵站的安全运行, 制约了工程效益的充分发挥和 灌区的可持续发展。2009 年,宁夏回族自治区发展和改革委 员会批复对中卫市南山台扬水泵站进行更新改造, 并对各泵 站配套自动化监控系统。基于此要求, 南山台扬水洜站开始 进行自动化监控系统改造, 确保泵站自动化监控系统的应用 效率。

\section{2 需求分析}

(1)综合参考系统分析：对实时采集数据进行计算分析, 并将计算结果存储在数据库中, 方便运行人员对百站设备运 行情况实现全面监管。

(2)安全运行监视: 在对采集到的数据信息进行分析处理 后,与数据库中的预设信息进行对比, 发现数据异常后及时 通知值班人员进行处理, 并同时做好数据记录。

(3) 实时监视: 对各泵站设备的实时运行参数和运行状态 进行实时监视显示, 并在确定设备存在故障情况时, 自动推 出事故或者故障画面。另外, 在对某设备进行操作时, 还会自 动推出该设备的相关操作画面和过程监视画面 ${ }^{[1]}$ 。

(4)控制调节: 根据预设原则或者人工操控指令对各泵站 设备进行调节控制。具体控制方式会采用现(就)地控制层、 
泵站(主)控层控制、远方调度三级控制方式。

(5)数据通信: 系统与调度中心之间采用无线传输技术进 行数据传输; 系统与各泵站设备之间采用以太网和 TCP/IP 协议达成数据交互 ${ }^{[2]}$, 其中上下实时数据采用广播通信方式, 使所有节点能够同时接收到实时数据信息, 并将数据存入数 据库中。下行控制命令将会由节点设备发出, 在经过系统校 准检验后, 通过点对点的方式发送到各 LCU 节点。

(6)系统实时数据库:采用网络型分布式数据库,所有数 据共享均会网络通信的方式达成。在系统中, 主站将会设置 有完整的系统实时数据库和历史数据库, 而其他各节点则只 会保留与节点功能相关的实时数据库。

\section{3 子系统架构设计}

中卫市南山台扬水百站自动化监控系统主要由网络及 通信系统、计算机监控系统、微机保护系统、视频监视系统、 软件系统等子系统构成, 这些子系统相结合后实现对泵站联 合调度、水资源优化配置及动态管理效果, 从而有效提高了 南山台扬水泵站的自动化水平, 提高区域水利工程的管理效 率及效果, 实现水资源、水利工程的数据化、信息化管理。各 子系统实际情况如下。

\section{1 网络及通信系统}

首先, 在沙坡头区南山台电灌站设立调度中心, 配置相 应的网络及通信系统设备; 其次, 在工程中所涉及的 4 座泵 站及渠首引水口处设置信息节点、视频节点及语音通话节 点, 为确保系统应用效果, 需要在 5 处位置中分别设置一套 信息节点、视频节点及语音通话节点 ${ }^{[3]}$; 再次, 通过光纤沟通 一个可以覆盖、连接 4 座泵站和调度中心的光纤通信网络; 最后, 由于渠首引水口距调度中心距离小于 $1 \mathrm{~km}$ 且无明显 影响无线传输的障碍物, 渠首引水口与调度中心通过无线微 波传输。

\section{2 计算机监控系统}

调度中心监控系统主要负责对各泵站的监控数据进行 汇总、分析、处理, 是计算机监控系统的核心组成部分; 一泵 站计算机监控系统主要监控该站专用变电站各电量、开关量 等; 各泵站监控系统对各泵站进、出水池、拦污栅、集水井等 水位计及出水管道压力等诸多数据信息进行收集, 为远程调 度中心监控系统的监控处理提供数据支持。

\section{3 微机保护系统}

南山台扬水百站更新改造工程对南山台一泵站的 18 套 微机保护系统进行更新改造, 其中更换的设备包括: $6 \mathrm{kV}$ 主 变低压进线保护装置 2 台; 电动机保护装置 10 台; 母联保护 装置 1 台; 站用变保护装置 2 台; PT 测控装置 2 台; PT 并列 切换装置 1 台。

\section{4 视频监视系统}

整个视频监视系统将会采用光纤同步传输网络实现视 频图像的实时传输。通过视频监视系统, 运行人员可以在调 度中心中对各泵站及渠首引水口进行远程图像监控、图像切 换、云台镜头控制以及历史图像查看等效果, 提高系统监控 管理效果的同时, 降低运行人员的工作强度和管理成本。

\section{5 软件系统}

软件系统需要能够实现数据信息的快速收集, 并根据收 集的数据信息进行快速分析处理, 确定各系统设备的实际运 行情况, 并根据不同的设备故障问题, 自动做出不同的解决 措施。为能够满足上述要求, 自动化监控系统将会配置联合 调度管理系统、洜站管理系统、综合数据库系统等软件系统, 实现系统的自动化监控管理, 并及时将监管数据存储到数据 库中, 供运行人员实时进行查询分析使用。

\section{4 结语}

百站作为水利工程的基础工程之一, 其将会承担着区域 内防洪、排涝、抗旱、灌溉等诸多方面的功能, 在防洪、农业发 展等方面均发挥出了极为重要的作用。然而中国很多洜站都 始建于 20 世纪末期, 自动化水平相对较低, 不符合当今时代 需求, 所以需要进行相应的自动化改造。据此, 本文以中卫市 南山台扬水泵站为例, 介绍了扬水泵站更新改造工程中自动 化扬水百站的相关设计架构, 结合实际情况来看, 该系统已 经平稳运行多年, 并在本地区水利管理过程中发挥出了良好 应用成效,所以值得进行普及推广使用。

\section{参考文献}

[1] 李兆吉.电气自动化控制系统在江都三站改造工程中的应用 $[\mathrm{J}]$. 中国水能及电气化,2020(2):34-38.

[2] 潘自林, 李晓刚. 梯级扬水百站自动化智能控制系统运行探究 [J].智能城市,2019(20):197-200.

[3] 刘明.自动化监控系统在拦河闸工程设计中的应用[J].水利建设 与管理,2018(8):46-49. 